Wagner Jorge dos Santos ${ }^{1}$ Karla Cristina Giacomin ${ }^{2}$ Josiane Katherine Pereira ${ }^{1}$ Josélia de Oliveira Araújo Firmo ${ }^{2}$

1 Programa de PósGraduação em Ciências da Saúde, Laboratório de Epidemiologia e Antropologia Médica, Centro de Pesquisas René Rachou, Fiocruz. Av. Augusto de Lima 1715/610, Barro Preto. 30.190-002 Belo Horizonte MG. wagnerjorge@cpqrr.fiocruz.br ${ }^{2}$ Núcleo de Estudos em Saúde Pública e

Envelhecimento, Fiocruz, UFMG.

\title{
Enfrentamento da incapacidade funcional por idosos por meio de crenças religiosas
}

\author{
Coping with functional disability among the elderly \\ by means of religious beliefs
}

\begin{abstract}
The way people deal with the stress of life is known as the process of coping or confrontation. We speak of religious coping when a person uses religious belief and behavior to facilitate problem solving, to prevent or alleviate stressful negative emotional consequences, notable among which is functional disability. The objective of this study was to investigate the role of religion as a strategy for coping with disability among the elderly. A qualitative approach, consisting of an observational ethnographic study was employed, the sample for which included 57 elderly individuals from Bambui, Minas Gerais. The model of signs, significances and actions was used in collecting and analyzing data. The religiosity of the elderly respondents suggested that their religious beliefs and traditions help explain and address the suffering experienced by them in the presence or imminence of functional disability. Religious coping reinforces the fatalism existing in the religious belief that mirrors the inevitability of old age with disability as an accepted and natural social code, but also helps to minimize the social responsibility for the care of the elderly and reveals the disbelief in existing public health services.

Key words Religious coping, Elderly, Functional disability, Public health services
\end{abstract}

Resumo O modo como as pessoas lidam com o estresse da vida é conhecido como o processo de coping ou enfrentamento. Fala-se de coping religioso quando a pessoa utiliza crenças e comportamentos religiosos para facilitar a resolução de problemas, prevenir ou aliviar consequências emocionais negativas estressantes, dentre as quais a incapacidade funcional. O objetivo do presente trabalho foi investigar o papel da religiosidade como estratégia de enfrentamento da incapacidade funcional entre idosos. Foi utilizada a abordagem qualitativa, constituindo-se em um estudo etnográfico observacional, cuja amostra incluiu 57 idosos da cidade de Bambuí, Minas Gerais. O modelo dos signos, significados e ações foi utilizado na coleta e análise dos dados. A religiosidade dos idosos entrevistados sugere que suas crenças e tradições religiosas ajudam a explicar e a enfrentar o sofrimento experimentado por eles na vigência ou iminência da incapacidade funcional. $O$ enfrentamento religioso reforça o fatalismo presente na crença religiosa que espelha a fatalidade da velhice com incapacidade como um código social aceito e naturalizado, mas também colabora para minimizar a responsabilidade social pelo cuidado do idoso e revela a descrença nos serviços públicos de saúde existentes.

Palavras-chave Enfrentamento religioso, Idoso, Incapacidade funcional, Serviços públicos de saúde 


\section{Introdução}

Nos dias atuais cresce o interesse acerca da relação entre religião e saúde nas ciências sociais, comportamentais e da saúde segundo apontam jornais e revistas de impacto na saúde pública e na medicina ${ }^{1}$. Nas ciências da saúde, os trabalhos constatam a diversidade de implicações que a religiosidade pode ter no processo saúde/doença ${ }^{2}$ e enfatizam seu papel enquanto estratégia de enfrentamento na experiência desse processo.

As estratégias de enfrentamento com base na religiosidade incluem o uso da religião, espiritualidade ou fé para lidar com o estresse e as consequências negativas geradas pela experiência dos problemas da vida ${ }^{3,4}$. Essas estratégias podem ser classiûcadas como positivas ou negativas, conforme associadas, respectivamente, a melhores ou a piores resultados na saúde física/mental ${ }^{3}$.

O conceito de enfrentamento religioso delineado a partir do estudo cognitivista do estresse e do coping ${ }^{3}$ é entendido como uma transação interativa na qual pessoa e ambiente estabelecem relações dinâmicas, mutuamente recíprocas e bidirecionais ${ }^{5,6}$. Nesse Modelo Interativo de Estres$\mathrm{se}^{6}$, o enfrentamento é definido como "esforços cognitivos e comportamentais voltados para o manejo de exigências ou demandas internas ou externas que são avaliadas como sobrecarga aos recursos pessoais"7, sendo a seleção das respostas de enfrentamento mediada por avaliações cognitivas $^{5}$. Nestas, o pensar e o agir configuram o percurso do sujeito diante de sua experiência de enfrentamento de situações estressantes e negativas. Para isso, o sujeito faz uma avaliação primária analisando a situação em seus aspectos desafiadores, prejudiciais e ameaçadores, e uma avaliação secundária em que são analisados os recursos disponíveis para o enfrentamento da situação $^{5}$. As repostas de enfrentamento são as alternativas onde o elemento negativo e de estresse do ambiente é controlado, podendo ser classificadas em duas categorias de acordo com a sua função: o enfrentamento centrado no problema e o enfrentamento centrado na emoção ${ }^{5,8,9}$.

$\mathrm{O}$ enfrentamento centrado no problema refere-se aos esforços para administrar ou alterar os problemas, ou melhorar o relacionamento entre as pessoas e o seu meio ${ }^{9}$. São estratégias adaptativas voltadas para a realidade, que buscam o manejo ou a modificação da situação causadora de estresse, na tentativa de remover ou abrandar a fonte estressora e de controlar ou lidar com a ameaça, dano ou desafio ${ }^{5}$.

O enfrentamento centrado na emoção é a tentativa de substituir ou regular o impacto emoci- onal do estresse no indivíduo. Deriva de processos defensivos e faz com que as pessoas evitem confrontar conscientemente a realidade de ameaça ${ }^{9}$. Sua função primordial é regular a resposta emocional causada pela situação problema com a qual a pessoa se depara. Apresenta-se em atitudes de afastamento como negação ou esquiva em relação à fonte de estresse ${ }^{5}$. Essas duas formas de enfrentamento são inter-relacionadas, visto que as pessoas, diante de um mesmo evento estressor podem utilizá-las simultaneamente.

Dois pressupostos do processo de enfrentamento são importantes: a) os eventos são interpretados pelas pessoas de acordo com os significados que elas lhes atribuem. Nessa perspectiva, o que torna uma experiência estressante não é o evento em si, mas a avaliação do sujeito sobre o evento, traduzindo a situação como negativa e estressante ${ }^{5,10}$; b) a interpretação do sujeito é influenciada pela cultura, o que modela a avaliação da situação, o quadro de referência e os sistemas de orientação das pessoas no mundo, privilegiando estratégias de enfrentamento muito particulares para cada contexto sociocultural ${ }^{5}$.

Na velhice, uma condição que pode gerar sofrimento é a incapacidade funcional, compreendida como o conjunto de limitações e dificuldades que o indivíduo apresenta ao realizar atividades cotidianas em qualquer domínio da vida ou a restrição na sua participação social ${ }^{11,12}$. A avaliação que o sujeito idoso faz da sua experiência corporal de incapacidade considera o seu quadro de referência pessoal, sustentado nos dados da cultura que confere significado à sua experiência. O modo como a pessoa lida com o estresse resultante da experiência da incapacidade funcional é também um processo de coping ou enfrentamento.

Portanto, no contexto de progressivo envelhecimento populacional brasileiro, é importante conhecer como as pessoas lidam com seus processos de envelhecer e como os enfrentam. Se as ciências da saúde têm buscado conhecer e explorar a diversidade de implicações que as estratégias de enfrentamento podem ter nos fenômenos relacionados à saúde e ao adoecer ${ }^{2}$, de modo similar, deveriam se interessar pelo contexto sociocultural do envelhecer no nosso meio. O processo de enfrentamento ao envelhecer com incapacidade, especificamente o coping religioso, ainda é pouco estudado no Brasil embora haja muitas evidências empíricas de que este último esteja associado ao processo saúde/doença e à qualidade de vida ${ }^{3}$. A necessidade de aumentar a produção acadêmica científica de conhecimento nessa área é justificada pela relevância da temática 
religião na sociedade brasileira ${ }^{5}$, uma vez que o Brasil é o país com maior número de católicos no mundo ${ }^{13}$ e que a atual geração de idosos sofreu grande influência desse matiz religioso em sua formação. O objetivo deste estudo é investigar o papel da religiosidade como estratégia de enfrentamento da incapacidade funcional entre idosos participantes da Estratégia Saúde da Família, residentes na cidade de Bambuí, MG.

\section{Percurso Metodológico}

\section{Quadro Teórico}

Uma das grandes contribuições da antropologia para saúde foi a construção de um quadro conceitual e metodológico inovador que investiga o envelhecimento a partir da perspectiva êmi$\mathrm{ca}^{14}$. Nessa metodologia a interpretação do cientista é construída na visão dos entrevistados e não como uma discussão da concepção do pesquisador ou da literatura ${ }^{15}$. Na presente pesquisa, o idoso foi convocado a falar sobre a vida e sobre si, especificamente sobre suas condições de saúde e eventual experiência de incapacidade funcional. Isso possibilitou ao pesquisador o mergulho no ambiente local e cultural desse idoso, lugar onde ele se organiza e lhe confere significados particulares sobre a sua própria experiência.

A abordagem interpretativa da antropologia utilizada na presente pesquisa muda o foco da doença como uma entidade biológica para a experiência da doença em um determinado contexto social e cultural. Ressalte-se que em humanos, os fenômenos nunca são apenas um, pois eles estão sempre imbuídos de significado na junção entre os quadros pessoal e coletivo ${ }^{16}$. Esse significado é apropriado pelos pesquisadores da antropologia interpretativa como o elemento que influencia o curso da doença moldando a experiência subjetiva e o comportamento individual e social em resposta à doença ${ }^{16}$.

Ampliando a possibilidade de aplicação do conceito de experiência, a religião pode ser individual, mas atua coletivamente ${ }^{17}$. Essa distinção feita por Geertz $^{18}$ relativiza a religião tal como concebida por William James no final do século XIX, como "os sentimentos, atos e experiências de homens individuais em sua solidão, na medida em que eles se apreendem como estando relacionados com o que possam considerar divino"19.

A experiência religiosa concebida por William James como simples sentimento produz um sentido individualista, com uma proposta mais psicológica e subjetiva. Em Geertz a religião deixa de ser um assunto privado e individual apenas, atingindo avassaladoramente, por meio da cultura, o público em suas múltiplas expressões ${ }^{20}$. O movimento das questões e identidades religiosas vai em direção ao centro da vida social. Para Geert $^{18}$ a contemporaneidade faz evidenciar que o "beliscão do destino" - metáfora da religião em William James - não está escondido no silêncio da alma solitária, mas parece estar bem presente no campo social e cultural.

No universo da cultura, os símbolos sagrados sintetizam o ethos de um povo e a sua visão de mundo ${ }^{21}$. A religião para Geertz ${ }^{21}$ é um sistema simbólico responsável por um determinado tipo de comportamento social que estrutura a experiência e a expressa em certa coerência prática. Assim a religião pode ser definida como "um sistema de símbolos que atua para estabelecer poderosas, penetrantes e duradouras disposições e motivações nos homens através da formulação de conceitos de uma ordem de existência geral e vestindo essas concepções com tal aura de fatualidade que as disposições e motivações parecem singularmente realistas" 21 .

A religiosidade diz respeito ao nível de envolvimento religioso e o reflexo desse envolvimento na vida da pessoa, o quanto isso influencia seu cotidiano, seus hábitos e sua relação com o mun$\mathrm{do}^{22}$. Na presente pesquisa o termo religião/religiosidade reflete a experiência do grupo estudado e refere-se especificamente ao Cristianismo, nas tradições religiosas com sua vertente fundamentalmente católica.

\section{Local de estudo}

A pesquisa foi conduzida na área urbana da cidade de Bambuí, município do centro-oeste do estado de Minas Gerais que possui uma população estimada em 2010 de 22.734 habitantes ${ }^{23}$. O município passa por um progressivo fenômeno de urbanização, com evolução significativa na população rural que representava $84 \%$ em 1950, 27\% em 1991 e em 2010 representa apenas 15\% da população total do município. A composição etária da população também apresenta envelhecimento progressivo: em 1960, 3,8\% dos habitantes apresentavam 60 ou mais anos de idade; 5,1\% em 1970, 7,3\% em 1980 e 9,3\% em 1991, e segundo o senso do IBGE de 2010 essa população passou a representar $15,9 \%$. O crescimento da população idosa neste município foi maior $(7,1 \%)$ do que no país em geral $(6,2 \%)$ no período compreendido entre 1991 e $2009^{24}$. O Mapa da Pobreza e Desigualdade do município mostra que há uma incidência de $32,47 \%$ da população 
em estado de pobreza ${ }^{23,25}$. Não existem instituições de longa permanência para idosos ${ }^{26}$. É forte a presença da religião católica no município, representando $88 \%$ da população total em $2010^{23}$.

\section{População de estudo}

Para reconstruir o universo de representações (maneiras de pensar) e comportamentos (maneiras de agir) associados à incapacidade funcional foram selecionados 57 idosos com 60 anos ou mais residentes em Bambuí, cadastrados nas 6 Unidades Básicas de Saúde e assistidos pela Estratégia Saúde da Família. A escolha dos participantes do estudo foi baseada em critérios que visaram garantir a heterogeneidade dos participantes, segundo o território da ESF, o gênero, a idade e a condição funcional. Somente foram selecionados e entrevistados idosos sem alterações cognitivas que impedissem a realização das entrevistas.

Na perspectiva da abordagem qualitativa foi utilizado o critério de saturação para regular o tamanho da amostra ${ }^{27}$. Para isso, foram identificados fatores operacionais de redundância e repetição dos dados, fatores teóricos de consistência e representatividade de elementos associados à incapacidade e à qualidade das informações obtidas sobre funcionalidade, contribuindo para a decisão de um determinado ponto de saturação amostral.

\section{Coleta e análise dos dados}

Foram realizadas entrevistas com os idosos em seu domicilio. A técnica de pesquisa utilizada na coleta de dados foi a entrevista semiestruturada, permitindo a ampliação do campo de fala dos idosos pertencentes à amostra. Todas as entrevistas foram gravadas após consentimento livre e esclarecido dos informantes.

O modelo de Signos, Significados e Ações, desenvolvido por Corin et al. ${ }^{28}$ foi utilizado na coleta e análise dos dados, em razão do mesmo permitir a sistematização dos elementos do contexto que participam da construção de maneiras típicas de pensar e agir diante da incapacidade ${ }^{14}$. Este modelo tem origem na corrente interpretativa em antropologia, na qual emerge uma nova concepção da relação entre indivíduos e cultu$\mathrm{ra}^{29}$, segundo a qual a cultura constitui um universo de símbolos e significados que permite os sujeitos de um grupo interpretar suas experiências e guiar suas ações ${ }^{21}$.

Corin et al. ${ }^{28}$ parte do comportamento concreto dos indivíduos para reconstruir as lógicas conceituais subjacentes a esses comportamen$\operatorname{tos}^{14}$. Assim, para reconstruir o universo de representações e comportamentos associados à incapacidade pelos idosos residentes em Bambuí as entrevistas tiveram inicialmente algumas perguntas geradoras que conduziram a perguntas abertas abordando o contexto biopsicossocial, os recursos, o impacto e o significado da incapacidade.

As entrevistas gravadas foram posteriormente transcritas, permitindo na leitura atenta e cuidadosa a identificação de unidades de significado que compõem a comunicação e a criação das categorias analíticas, fundamentando a análise dos dados na interação entre as diferentes categorias e sua articulação com o contexto sociocultural vigente ${ }^{30}$. Nas unidades de significado foi destacado o sentido geral da fala dos idosos e para as categorias analíticas, as frases, palavras, adjetivos, concatenação de idéias, e sentidos específicos da fala dos entrevistados que estivessem associados às estratégias de enfrentamento da incapacidade funcional. Para assegurar o anonimato dos entrevistados eles foram identificados pelo sexo $(\mathrm{M}$ ou $\mathrm{H})$ e pelo número de sequência de realização da entrevista.

\section{Aspectos éticos}

Esta pesquisa é parte de um projeto maior intitulado Abordagem Antropológica da Dinâmica da Funcionalidade em Idosos que foi submetido à análise e aprovado pelo Comitê de Ética em pesquisa com seres humanos do Centro de Pesquisa René Rachou. Todos os participantes assinaram um termo de consentimento, em acordo com a Resolução n¹96/1996 do Conselho Nacional de Saúde ${ }^{31}$.

\section{Resultados e Discussão}

Considerando que os comportamentos religiosos são bastante frequentes na idade avançada ${ }^{2}$, a religiosidade mostrou-se um quadro de referência pessoal importante para os idosos de Bambuí. Isso se revela na sua maneira de pensar a vida e experimentar o cotidiano, sendo evidenciado na cultura pelos signos que sustentam coletivamente o seu discurso religioso. Para Geertz ${ }^{21}$ o discurso cultural denota um padrão de significados construídos e transmitido historicamente onde se desenvolve e perpetua o conhecimento e as maneiras de atuar na vida.

O discurso apresentado no campo de fala dos idosos bambuienses evidenciou a religiosidade 
como estratégia recorrente de enfrentamento da incapacidade funcional e serviu de base para o processo investigativo que se desenhou. A direção desse percurso procurou compreender a forma como era trazida a religiosidade na produção discursiva dos idosos, os significados da religiosidade na composição da estratégia de enfrentamento, a tipologia específica de enfrentamento que era conseguido e as respostas produzidas por quem utilizava esse tipo de estratégia.

Na leitura minuciosa dos discursos transcritos, o tratamento dado às falas dos idosos possibilitou a identificação de três unidades de significados: Velhice, Incapacidade e Religiosidade. Em cada unidade de significado foram discriminadas várias Categorias Analíticas de acordo com os signos percebidos e associados pelos sujeitos às estratégias de enfrentamento da incapacidade funcional. Tal critério permitiu observar que os elementos culturais presentes na manifestação discursiva da religiosidade como enfrentamento da incapacidade funcional sustentavam dois signos que, além de recorrentes, evidenciaram um núcleo dos significados que davam corpo às ações, por eles sustentadas: o signo não dou conta e o signo graças a Deus. A partir deles, na perspectiva da descrição densa proposta por Geertz ${ }^{21}$, foi analisada minuciosamente a experiência corporal dos idosos com a incapacidade funcional e a religiosidade como estratégia de enfrentamento.

\section{O corpo da velhice incapaz}

A experiência corporal dos idosos de Bambuí é mediada pelos signos presentes no seu grupo social, produzindo um significado particular para a vivência da incapacidade funcional. Nessa perspectiva, o corpo funciona como um "suporte de signos" das mudanças no comportamento e nas estruturas do corpo, ajudando a consolidar o imaginário de incapacidade ${ }^{32}$.

Na percepção dos idosos a incapacidade é avaliada a partir da declaração indicativa de dificuldade ou de necessidade de ajuda, principalmente em tarefas básicas de cuidados pessoais e em outras mais complexas necessárias para viver independente na comunidade ${ }^{33}$. Não dar conta reflete a sensação produzida pelo corpo diante da incapacidade funcional, sendo definido no campo de fala do idoso como aquele que se modificou negativamente no tempo, alterando sua relação com o cotidiano da vida e existência no mundo, anunciando sua finitude: Trabalhar num serviço pesado, eu não dou conta. Andar pra distância longe, eu não dou conta... e a gente vai acabando aos poucos. (H49, 77 anos, solteiro). Enve- lhecer com incapacidade é uma questão de tempo. Quando perguntado sobre como avalia sua saúde, o mesmo entrevistado afirma: Mais ou menos, porque, graças a Deus, ainda tô andando, consigo tomar banho, fazer minha bóia. Ainda não tô caducando (risos) [...] Graças a Deus (H49, 77 anos, solteiro) (grifo nosso).

A incapacidade é experimentada como natural (é da idade), irreversível (não tem jeito) e dolorosa (tudo dói), e pode ser traduzida e sintetizada na expressão: não dou conta. A pessoa não dá conta hoje de algo que um dia dera e que antes conseguia fazer com facilidade e naturalidade, como descreve essa entrevistada: Não dou conta de fazer nada não. Nem assim de noite, de modo de eu cobrir, não dou conta de puxar um lençol pra me cobrir com a mão. O pé também, já vai enrolando tudo (M8, 83 anos, viúva).

Por outro lado, o corpo do passado insiste em lhe lembrar de um corpo ideal e o corpo real produz uma experiência de não ser mais o que era. Ou seja, a perda do corpo que era capaz de produzir desvela a perda da própria vida. Daí a Experiência de Esvaziamento, tantas vezes explicitada pelos idosos do grupo pesquisado e metaforizada na experiência corporal. Ao ser indagado sobre por que a perna ficou bamba e frouxa, esse nonagenário explica: Não firma. Parece que... não é como era. [...] Uai, o que mudou é que, eu gostava de sair e caçar, sabe, ir pro mato caçando, quando eu aposentei, agora eu não posso sair, fico querendo o rio e não posso. É ficar quieto. (H46, 90 anos, viúvo).

Nesse não dô conta, quando as estratégias de enfrentamento da incapacidade funcional estabelecem o seu foco no problema, não ocorre o manejo ou modificação da situação de incapacidade funcional causadora do estresse. A saída encontrada é deixar de lado o que não consegue mais fazer. Uma senhora expressa claramente: $E u$ faço assim, quando a gente não dá conta de nada mais, eu tenho que largar. Vai largando! (M4, 81 anos, viúva).

Outra alternativa para quem experimenta esse corpo que envelhece e se torna incapaz é a construção de estratégias de enfrentamento com foco nas emoções, dentre as quais se destaca a estratégia religiosa.

\section{O enfrentamento religioso da incapacidade}

O enfrentamento religioso para os idosos de Bambuí tem como função primordial regular a resposta emocional causada pela experiência corporal de incapacidade e reelaborar essa experiên- 
cia. Isso se faz a partir do olhar de quem crê em uma Alteridade Divina que funciona como a ponte entre o real - insuportável - do sujeito e uma realidade utópica melhor - em que se acredita imaginária, desejada, esperada.

Diante da incapacidade real, iminente ou temida, a pessoa idosa ao invés de blasfemar, responde a Deus com gratidão. No campo de fala dos idosos, mesmo doentes e incapacitados, é recorrente no enfrentamento religioso o signo Graças a Deus. Um dos entrevistados ao se referir à sua saúde informa: Mas eu, graças a Deus, até que lá vai tudo mais ou menos normal. (H3, 75 anos, casado); e outra senhora explica que está meio perrenguinha: $E$, mas graças a Deus eu firmei um pouco. (M27, 80 anos, solteira)

Nessa perspectiva o Graças a Deus se constitui em um signo que reflete a estratégia de enfrentamento religioso e produz no universo simbólico dos entrevistados uma codificação da restituição no esvaziamento causado pela incapacidade funcional. Pela fé no poder dessa Alteridade Divina em fazer as coisas acontecerem, a realidade indesejável pode ser transformada em algo mais suportável e percebida emocionalmente como boa. Graças a Deus revela que o sofrimento atual pode ser suportado na esperança por uma compensação implícita e vindoura de salvação da alma e do corpo. Independentemente da condição real desse corpo, o idoso crê em Deus, e por isso torna-se gratificante estar nessa condição mesmo se a realidade que o entrevistador observa é bastante diferente do que o discurso expressa.

Constata-se, portanto, um deslocamento do significado da incapacidade na sua concretude para um sentido emocional que tenta traduzir a experiência em algo bom e desejável. Isso acontece exatamente porque a religiosidade é configurada como uma experiência com a alteridade divina que tem a atribuição de produzir uma dupla restituição necessária à experiência da incapacidade funcional: primeiro ela restitui ao sujeito uma realidade suportável, pois no código da cultura, a bondade e a justiça de Deus conferem suporte àquele que Nele crê; segundo, ela restitui as ausências e perdas produzidas pelo problema corporal vivido, pois na experiência dos idosos a presença da Alteridade Divina preenche emocionalmente o esvaziamento causado pela incapacidade. Assim, ao agradecer por essa realidade encontra-se algo de bom nela, ao mesmo tempo em que é Deus quem o faz no lugar desse vazio. Finalmente, ela promete a vida eterna a esse corpo que sofre e que deixará de sofrer pela vontade de Deus.
De certo modo, a religiosidade explica a vida, atribuindo significados aos fatos ${ }^{34}$ e dando-lhe contornos de sentido que confortam. A religiosidade presente no campo de fala dos idosos entrevistados sugere que suas crenças e tradições religiosas ajudam a explicar e a enfrentar o sofrimento experimentado por eles, conforme explica esse senhor quando perguntado sobre como está sua saúde: ... Mais ou menos, porque graças a Deus ainda tô andando, eu consigo tomar banho, fazer a minha bóia. Ainda não tô caducando [risos] [...] Explicando que as coisas estão boas demais: ... Graças a Deus. [...] Respondendo sobre se tem amigos ou companhia: ...Graças a Deus. [...] Indagado sobre se é uma pessoa feliz: ...Graças a Deus. (H30, 76 anos, solteiro).

$\mathrm{Na}$ medida em que encontramos no código da cultura de uma sociedade cristã católica o mandamento do apóstolo Paulo que diz "Em tudo, dai graças, porque esta é a vontade de Deus em Cristo Jesus para convosco" (10 Tessalonicenses 5:18, grifo nosso $)^{35}$, podemos entender a explicação e o enfrentamento do sofrimento: tudo é graças a Deus. A explicação é feita na medida em que se reconhece Nele a fonte de todas as coisas, pois é Ele quem dá; enquanto o enfrentamento se realiza na medida da crença de quem crê, pois o agraciado é quem vive aquilo que agradece. Assim a pessoa suporta a realidade, pois acaba trazendo a vida para o lugar onde ela acontece, nesse "aqui e agora" da existência, nesse tempo presente: saúde tá boa, graças a Deus. Setenta e seis anos não é fácil não, né. (M39, 76 anos, Viúva).

Os idosos entrevistados buscaram na estratégia religiosa uma via de enfrentamento que tampona o estresse resultante de sua condição na existência, pois "não é fácil imaginar que nosso corpo, tão cheio de frescor e muitas vezes de sensações agradáveis, pode ficar vagaroso, cansado e desajeitado. [...] No fundo, não o queremos"36. As estratégias sustentadas na religiosidade servem como um amortecedor dos eventos negativos, como elementos protetores do "self, ajudando principalmente em situações de alta incontrolabilidade, servindo como elemento facilitador da aceitação da falta de controle, e preservando o self dos impactos negativos do estresse" ${ }^{37}$.

Por sua vez, em um estudo baseado na teoria do estresse e do coping, Folkman et al. ${ }^{38}$ demonstraram que pessoas idosas tendem a usar mais comportamentos de coping com foco nas emoções do que os jovens. Outras pesquisas mostram que a partir da meia-idade os sujeitos passam a dar maior valor e atenção aos aspectos internos do self, possibilitando abertura para per- 
cursos de encontro com os sentimentos e comportamentos religiosos ${ }^{39}$.

$\mathrm{O}$ enfrentamento religioso funciona como mediador entre as aflições, o medo, as tragédias e a realidade de quem envelhece e, especialmente, de quem convive com a incapacidade atual ou com o temor de que ela lhe ocorra no futuro. Se a incapacidade funcional metaforiza no corpo os significados de uma existência que se esvazia e termina, conforme os achados do presente trabalho, a cultura oferece na experiência religiosa a possibilidade de um enfrentamento dessa realidade.

Fatalismo e descrença nos serviços públicos de saúde

Em Bambuí, a cultura local opta pelo não enfrentamento da incapacidade, sendo reforçada pelo fatalismo presente na crença religiosa que espelha a fatalidade da velhice com incapacidade como um código social aceito e naturalizado. A cultura sustenta as representações e o discurso sobre o corpo e a saúde dos idosos a partir de estereótipos negativos em torno da associação entre velhice e doença. Na região de Bambuí, em um estudo de Uchôa et al. ${ }^{40}$ foi percebido que o olhar do outro sobre a velhice era carregado desse negativismo. Tal olhar corrobora o processo de naturalização e homogeneização da velhice e simultaneamente mantém os estereótipos transmitidos pela cultura.

Dessa forma, a percepção da velhice é relatada nas entrevistas como condição humana inexorável que decorre da idade e de um processo de involução, de caráter eminentemente negativo. $\mathrm{Na}$ visão de mundo do idoso, as falas naturalizam a decrepitude do corpo como se esta fosse inerente à velhice. Enquanto na perspectiva religiosa, traduz-se o sentido de um ethos em que a fatalidade da realidade se constitui na vontade de Deus. Ambas podem simplesmente revelar e reforçar comportamentos de uma pessoa que deve se sujeitar passivamente às contingências da vida.

A reprodução de estigmas e pré-conceitos quanto à velhice é reforçada pelos saberes constituídos nesse campo e pelos próprios idosos. Essa questão é percebida nos relatos dos idosos: ... Ah, eu penso que é ruim, ficar dependendo, depende dos outros demais né. Não pode fazer nada. Não é fácil não! Mas aí se Deus quiser né, se Deus quiser, a gente tá nas mãos de Deus. (M14, 88 anos, viúva); e... Ai depois que ele faltou eu falei: ah, se Deus quiser, eu vou acostumar! É Deus que vai me ajudar! E graças a Deus eu tenho... eu fico com Deus. Deus que é minha companhia. Não arrumei mais ninguém não, acostuma. Perguntada se morava sozinha, ela conclui: ... E Deus. (M27, 80 anos, solteira).

Esse tipo de crença religiosa fatalista tampona sofrimentos individuais, mas também colabora para minimizar a responsabilidade social pelo cuidado e revela a descrença nos aparelhos públicos existentes ${ }^{30}$.

Assim, os idosos bambuienses têm no enfrentamento religioso o conforto e a esperança para lidar com o contexto sociocultural em que envelhecem, com ou sem incapacidade. A incapacidade para muitos já é uma realidade, para outros é uma possibilidade temida; em ambas as situações, na fala deles, somente Deus é a resposta, somente em Deus há alívio. O Deus que lhes reserva este presente e este futuro e que pode livrá-los deles, se Ele quiser. No entanto, as demandas que fazem a Deus são da ordem do subjetivo, não são demandas materiais, não dizem respeito a recursos de saúde. Nessa perspectiva, a falta de ação dos serviços de saúde e das políticas públicas voltadas para o idoso reforça esse processo de aceitação e de naturalização da velhice com incapacidade. Isso fala a favor de uma cultura local em que a incapacidade funcional é compreendida como coisa da idade. Portanto, se é inexorável, não é necessário ou não se pode fazer nada no sentido de conferir ao processo de envelhecimento a possibilidade de outros itinerários de em-velho-ser.

Assim, tampouco existe a demanda por justiça social na fala de nenhum desses senhores e senhoras. Homens que foram explorados no trabalho como mão de obra pouco qualificada ou mulheres destinadas ao casamento ou ao cuidado dos mais velhos e dos mais novos, que abriram mão de seus desejos pessoais em nome da família; homens e mulheres que tiveram sua cidadania usurpada na ditadura brasileira e ainda guardam as marcas dessa opressão. Talvez isso explique o silêncio diante da falta de acesso a bens, recursos e direitos de cidadania durante toda a vida. Na velhice, talvez não acreditem, pois nunca conheceram a justiça social em nenhuma das etapas pregressas da vida. Velhos, talvez seja tarde demais para exigir. $\mathrm{O}$ que existe é um enorme vazio em termos de políticas de cuidado, ao longo de toda a vida deles.

No presente trabalho, chama a atenção o fato de que nenhum dos entrevistados se rebela contra Deus, questiona seus desígnios ou abandona a crença na misericórdia divina. Assim quando testados pelo abandono, pela incapacidade sem recursos, pelas dificuldades em sair e em ficar em casa, por deixar de ser notado, considerado, em 
razão de sua condição de velho, não se discute o que determina que alguns envelheçam com mais ou menos incapacidades do que outros.

$\mathrm{Na}$ cultura local, todos bebem do cálice que lhes está reservado, "graças a Deus". Há uma submissão total à vontade divina revelada na vida de hoje e de sempre - ou seria à falta de vontade dos homens em construir para todos a possibilidade de envelhecer com dignidade? A dignidade na velhice e a perspectiva de envelhecer ativamente não aparecem nas falas. Pelo contrário, os idosos reconhecem que estão sós na experiência da incapacidade e do envelhecer ou segundo suas crenças, estão com Deus, e, como estão próximos do fim, logo estarão com Ele. Eternamente.

\section{Conclusão}

O enfrentamento religioso é uma estratégia importante entre os idosos estudados, regula a resposta emocional causada pelo processo de incapacidade funcional, repara o esvaziamento existencial fazendo a pessoa sentir-se acolhida e apaziguada na realidade de seu corpo de hoje envelhecido e incapaz e restitui esse lugar vacante do Outro. Ao envelhecer com incapacidade, o sujeito experimenta em si um Outro que pode ser tanto o seu corpo potente e capaz que já não é mais, que lhe falta, pois ficou no passado; quanto à necessidade de um outro seu semelhante, esse que não sou eu, em quem busco apoio, que me faz companhia, podendo ser outro ser humano, mas que muitas vezes é Deus.

A incapacidade funcional faz ponte a uma dor que não se limita ao seu sentido objetivo e con- creto, mas envolve uma percepção subjetiva de uma perda de si mesmo. A dor desse corpo que envelhece e se torna incapaz se dá não simplesmente porque separa ou dificulta o acesso do sujeito aos objetos, mas porque separa e dificulta o acesso desse sujeito às pessoas. Por isso o Religare, na medida em que institui a companhia dessa Alteridade Divina presente na cultura, torna a vida mais suportável..

Na prática, a cultura local propõe o não enfrentamento da incapacidade e a religiosidade dos idosos reforça este fatalismo diante de uma situação que não admite alternativas ${ }^{40}$, produzindo passividade e ações de conformismo de quem não dá conta mais e que tendem a naturalizar o processo de envelhecimento com incapacidade, pois esta realidade Deus é quem quer, e assim o será até quando Ele quiser. Porém ficam expostos o abandono e a descrença em políticas públicas de cuidado.

A ausência de demandas materiais específicas relativas aos recursos de saúde que pudessem ser explicitadas pelos idosos de Bambuí sobre questões relacionadas ao enfrentamento da incapacidade funcional não significa necessariamente a ausência de uma necessidade concreta. $\mathrm{O}$ silêncio da parcela idosa da população reflete e revela a falta de ação dos serviços de saúde, evidenciando a barbárie cultural de naturalização e homogeneização da velhice abandonada, incapaz e limitada aos seus parcos recursos e a Deus, na transmissão do saber/fazer sobre a saúde da pessoa idosa.

$\mathrm{Na}$ cultura local, envelhecer com incapacidade e sem recursos é o que lhes está reservado, graças a Deus.

\section{Colaboradores}

WJ Santos, KC Giacomin, JK Pereira e JOA Firmo participaram igualmente de todas as etapas de elaboração do artigo. 


\section{Referências}

1. Alves RRN, Alves HN, Barboza RRD, Souto WMS. The influence of religiosity on health. Cien Saude Colet 2010; 15(4):2105-2111.

2. Teixeira JJV, Lefèvre F. Significado da intervenção médica e da fé religiosa para o paciente idoso com câncer. Cien Saude Colet 2008; 13(4):1247-1256.

3. Panzini RG, Bandeira DR. Coping (enfrentamento) religioso/espiritual. Rev Psiquiatr Clin 2007; 34(1):26-135.

4. Panzini RG, Bandeira DR. Escala de coping religioso-espiritual (escala cre): elaboração e validação de constructo. Psicol Estud 2005; 10(3):507-516.

5. Faria JB, Seidl EMF. Religiosidade e Enfrentamento em Contextos de saúde e Doença. Psicol Refl Crít 2005; 18(3):381-389.

6. Lazarus RS, Folkman S. Stress, Appraisal, and Coping. New York: Springer Publishing Company; 1984.

7. Folkman S, Lazarus RS, Gruen RJ, DeLongis A. Appraisal, Coping, Health Status, and Psychological Symptoms. J Pers Soc Psychol 1986; 50(3):571579.

8. Trentini M, Silva SH, Valle ML, Hammerschmidt KSA. Enfrentamento de situações adversas e favoráveis por pessoas idosas em condições crônicas de saúde. Rev Latino-Am Enfermagem 2005; 13(1):3845.

9. Lorencetti A, Simonetti AP. As estratégias de enfrentamento de pacientes durante o tratamento de radioterapia. Rev Latino-Am Enfermagem 2005; 13(6):944-950.

10. Pargament KI. The Psychology of Religion and Coping: Theory, Research, Practice. New York: The Guilford; 1997.

11. Camargos MCS, Perpétuo IHO, Machado CJ. Expectativa de vida com incapacidade funcional em idosos em São Paulo, Brasil. Rev Panam Salud Publica 2005; 17(5/6):379-386.

12. Brasil. Ministério da Saúde(MS). Portaria no 2.528 de 19 de outubro de 2006. Aprova a Política Nacional de Saúde da Pessoa Idosa. Diário Oficial da União 2006; 20 out.

13. Galvão WN. Hibridismo religioso na literatura brasileira. Imaginário 2006; 12(12):369-385.

14. Uchôa E. Contribuições da Antropologia para uma Abordagem das Questões Relativas à Saúde do Idoso. Cad Saude Publica 2003; 19(3):849-853.

15. Turato ER. Métodos Qualitativos e Quantitativos na Área da Saúde: Definições e seus Objetos de Pesquisa. Rev Saude Publica 2005; 39(3):507-514.

16. Corin E. The culture frame: Context and meaning in the construction of health. In: Amick BC, Levine S, Tarlov AR, Walsh DC, editores. Society and Health. Oxford: Oxford University Press; 1995. p. 272304.

17. Rodrigues E. A emergência dos novos movimentos religiosos e suas repercussões no campo religioso brasileiro. Numen, Rev Estud Pesqui Religião 2009; $12(1 / 2): 45-58$.

18. Geertz C. Religião: um beliscão do destino. In: Geertz C. Nova luz sobre a antropologia. Rio de Janeiro: Jorge Zahar Ed.; 2001.
19. James W. The Varieties of Religious Experience. In: James W. William James Writings 1902-1910. New York: The Library of America; 1987.

20. Menezes J. Tradição e experiência: uma inversão cultural do pensável pelas práticas. Antíteses 2010; 3(5):367-392

21. Geertz C. A Interpretação das Culturas. Rio de Janeiro: Livro Técnico e Científicos Editora; 1989.

22. Koenig HG, McCullough M, Larson DBB. Handbook of religion and health: a century of research reviewed. New York: Oxf University press; 2001.

23. Brasil. Instituto Brasileiro de Geografia e Estatística (IBGE). Dados gerais e informações estatísticas da cidade de Bambuí. [acessado 2011 out 4]. Disponível em: http://www.ibge.gov.br/cidadesat/topwindow. htm?1

24. Brasil. Instituto Brasileiro de Geografia e Estatística (IBGE). Observações sobre a evolução da mortalidade no Brasil: o passado, o presente e perspectivas. Rio de Janeiro: IBGE; 2010. [acessado $2011 \mathrm{dez} 27$ ]. Disponível em: http://www.ibge.gov.br/home/estatistica/ populacao/tabuadevida/2009/notastecnicas.pdf

25. Rios DFF, NMA, Loreto MDS, Fiúza ALC. O programa bolsa-família em um contexto de cidades rurais: o caso de Bambuí, MG. Oikos Viçosa 2011; 22(2):150-170.

26. Giacomin KC, Uchôa E, Firmo JOA, Lima-Costa MF. Projeto Bambuí: um estudo de base populacional da prevalência e dos fatores associados à necessidade de cuidador entre idosos. Cad Saude Publica 2005; 21(1):80-91.

27. Fontanella BJB, Ricas J, Turato ER. Amostragem por saturação em pesquisas qualitativas em saúde: contribuições teóricas. Cad Saude Publica 2008; 24(1):17-27.

28. Corin E, Uchôa E, Bibeau G, Kouma-Re B. Articulation et variations des systèmes de signes, de sens et d'actions. Psychopathologie Africaine 1992; 24:183204.

29. Uchôa E, Vidal JM. Antropologia Médica: Elementos Conceituais e Metodológicos para uma Abordagem da Saúde e da Doença. Cad Saude Publica 1994; 10(4):497-504.

30. Giacomin KC, Uchoa E, Lima-Costa MFF. Projeto Bambuí: a experiência do cuidado domiciliário por esposas de idosos dependentes. Cad Saude Publica 2005; 21(5):1509-1518.

31. Brasil. Ministério da Saúde(MS). Conselho Nacional de Saúde. Resolução no 196 de 10 de outubro de 1996. Diretrizes e Normas Regulamentadoras de Pesquisas Envolvendo Seres Humanos. Diário Oficial da União 1996; 16 out.

32. Neves RF, Nunes MO. Incapacidade, Cotidiano e Subjetividade: a narrativa de trabalhadores com LER/DORT. Interface (Botucatu) 2009; 13(30):55-66.

33. Parahyba MI, Simões CCS. A prevalência de incapacidade funcional em idosos no Brasil. Cien Saude Colet 2006; 11(4):967-974. 
34. Araújo MFM, Almeida MI, Cidrack ML, Queiroz HMC, Pereira MCS, Menescal ZLC. O papel da religiosidade na promoção da saúde do idoso. RBPS 2008; 21(3): 201-208.

35. A Bíblia Sagrada. Traduzida em português por João Ferreira de Almeida. 2a Edição revista e atualizada. Barueri: Sociedade Bíblica do Brasil; 2004.

36. Elias N. A Solidão dos Moribundos: seguido de en velhecer e morrer. Rio de Janeiro: Zahar; 2001.

37. Fortes-Burgos ACG, Neri AL, Cupertino APFB. Eventos Estressantes, Estratégias de Enfrentamento, Auto-Eficácia e Sintomas Depressivos entre Idosos Residentes na Comunidade. Psicol Refl Crít 2008; 21(1):74-82.

38. Folkman S, Lazarus RS, Pimley S, Novacek J. Age Differences in Stress and Coping Processes. Psycho Aging 1987; 2(2):171-184.

39. Goldstein LL, Neri AL. Tudo bem, graças a Deus. Religiosidade e Satisfação na maturidade e na Velhice. In: Neri AL, organizadores. Qualidade de Vida e Idade Madura. 3a Edição. Campinas: Papirus; 2003 p. 109-136.

40. Uchôa E, Firmo JOA, Lima-Costa MFF. Envelhecimento e saúde: experiência e construção cultural. In: Minayo MCS, Coimbra Júnior CEA, organizadores. Antropologia, Saúde e Envelhecimento. Rio de Janeiro: Fiocruz; 2002. p. 25-35.

Artigo apresentado em 05/08/2012

Aprovado em 17/09/2012

Versão final apresentada em 01/10/2012 